\title{
Sikap Konsumen terhadap Atribut Buah Jeruk Lokal dan Impor di Kota Denpasar
}

\author{
DIANAH UMI RAHMAWATI, MADE ANTARA, \\ I G. A. OKA SURYAWARDANI \\ Program Studi Agribisnis, Fakultas Pertanian, Universitas Udayana \\ Jalan PB. Sudirman Denpasar 80323 \\ Email: dianaumirahma@gmail.com \\ antara_unud@yahoo.co.id
}

\begin{abstract}
Consumer Attitudes Toward Attributes of Local and Import Orange in Denpasar
\end{abstract}

Efforts to meet the needs of orange fruit to the community is reflected by the number of orange fruit imported into indonesia.Various types of orange on the market will affect consumer attitudes in buying local and imports orange fruit that will increase the competition's heat between local and imports orange fruit in Denpasar. The aims of this study are to determine the consumer attitudes toward orange fruit attributes, knowing the competitiveness of local orange fruit viewed from consumer attitudes toward the attributes of local and imports orange fruit in Denpasar. Data collection was conducted at Badung Market, Kreneng Market, Tiara Dewata Supermarket, Hardy's Supermarket and Moena Fresh Fruit Shop located in Denpasar. Determination of samples by accidental sampling method with the number of samples of 60 respondents. Fishbein shows more positive consumer attitudes toward imported orange fruit attributes than local orange fruit. The overall meaning of imported orange fruit is superior to that of local orange fruit for the tendency of competitiveness of local orange fruit is still lower with imported orange fruit.

Keywords: importance, beliefs, attitudes, oranges, competitiveness

\section{Pendahuluan}

\subsection{Latar Belakang}

Buah-buahan memiliki fungsi yang penting bagi tubuh karena mengandung vitamin, mineral, serat dan sebagai sumber antioxsidan yang bermanfaat bagi kesehatan tubuh. Perlunya mengonsumsi buah-buahan dalam jumlah cukup sangat dibutuhkan oleh tubuh manusia. Akan tetapi, walaupun konsumsi buah-buahan dalam jumlah cukup sangat diperlukan nyatanya tingkat konsumsi buah-buahan dan sayursayuran di Indonesia masih tergolong rendah. Namun seiring meningkatnya kesadaran masyarakat akan hidup sehat dan gizi seimbang telah berimbas pada meningkatnya konsumsi dan permintaan akan berbagai produk sayuran dan buah-buahan (Zulkarnain, 2010).

Salah satu buah yang banyak dikonsumsi oleh masyarakat adalah jeruk. Berdasarkan proyeksi permintaan jeruk yang direpresentasikan sebagai proyeksi 
konsumsi pada tahun 2015 s.d 2019, konsumsi jeruk untuk rumah tangga meningkat dengan rata-rata pertumbuhan sebesar 0,52\%/kg/kapita/tahun (Pusdatin, 2015). Namun, produksi buah jeruk di Indonesia mengalami fluktuasi setiap tahunnya. Jika dilihat rata-rata pertumbuhan produksi buah jeruk selama 2011 s.d 2015 mengalami penurunan sebesar 1,49\% per tahun (Pusdatin, 2015). Upaya memenuhi kebutuhan buah-buahan untuk masyarakat dicerminkan dengan banyaknya buah-buahan impor yang masuk ke Indonesia. Konsumen akan mempertimbangkan terlebih dahulu untuk menetapkan pilihan dengan mengevaluasi atribut yang ada dalam buah jeruk. Beragamanya jenis jeruk yang ada di pasaran akan mempengaruhi sikap konsumen dalam membeli buah jeruk lokal ataupun jeruk impor. Sikap konsumen yang positif terhadap atribut yang ada didalam produk akan mendorong konsumen untuk membeli produk tersebut. Buah jeruk impor yang marak dipasaran bersaing ketat dengan jeruk lokal yang ada di Kota Denpasar yang merupakan salah satu daerah dengan konsumen yang banyak mengonsumsi buah jeruk lokal dan impor di Provinsi Bali. Masyarakat Bali saat ini cenderung membeli buah impor untuk upacara keagamaan khususnya dalam rangkaian buah (gebogan) karena beberapa hal, antara lain gengsi, lebih menarik dari segi penampilan dan atribut (Suryawardani, 1999)

Kajian untuk menilai, mengukur, dan menafsirkan keinginan, sikap dan perilaku konsumen perlu dilakukan sebagai salah satu upaya meningkatkan daya saing (Kotler, 2003). Dengan melihat sudut pandang konsumen bagaimana buah jeruk lokal dapat memenuhi kebutuhan dan keinginan konsumen akan meningkatkan agribisnis jeruk dalam negeri. Berdasarkan uraian permasalahan diatas, maka peneliti tertarik meneliti sikap konsumen terhadap atribut yang terdapat dalam buah jeruk lokal dan impor untuk mengetahui daya saing buah jeruk lokal di Kota Denpasar.

\subsection{Rumusan Masalah}

Berdasarkan latar belakang di atas maka rumusan masalah dalam penelitian sebagai berikut.

1. Bagaimana sikap konsumen terhadap atribut-atribut buah jeruk lokal dan impor di Kota Denpasar?

2. Bagaimana daya saing buah jeruk lokal dilihat dari sikap konsumen terhadap atribut buah jeruk lokal dan impor?

\subsection{Tujuan Penelitian}

Berdasarkan rumusan masalah yang telah diuraikan di atas, maka tujuan dari penelitian ini sebagai dibawah ini.

1. Untuk mengetahui sikap konsumen terhadap atribut-atribut buah jeruk lokal dan impor di Kota Denpasar

2. Untuk mengetahui daya saing buah jeruk lokal dilihat dari sikap konsumen terhadap atribut buah jeruk lokal dan impor 


\section{Metode Penelitian}

\subsection{Lokasi dan Waktu Penelitian}

Lokasi penelitian ini dilakukan di Pasar Badung, Pasar Kreneng, Supermarket Tiara Dewata, Supermarket Hardy's, dan Toko Buah Moena Fresh yang berada di Kota Denpasar, Provinsi Bali. Penelitian ini dimulai pada bulan April s.d Juni 2017. Penentuan lokasi penelitian dilakukan secara sengaja (purposive), yaitu penentuan daerah penelitian yang diambil secara sengaja berdasarkan pertimbangan tertentu.

\subsection{Populasi dan Sampel}

Populasi dalam penelitian ini adalah seluruh konsumen buah jeruk lokal dan jeruk impor yang berada di Kota Denpasar yang jumlahnya tidak diketahui. Pengambilan sampel ditentukan dengan metode accidental sampling. Responden adalah konsumen jeruk lokal dan impor yang kebetulan ditemui di lokasi penelitian saat sedang membeli atau pernah membeli buah jeruk. Jumlah sampel dalam penelitian ini ditentukan secara sengaja (purposive) sebanyak 60 responden.

\subsection{Data dan Metode Pengumpulan Data}

Jenis data yang digunakan yaitu data kuantitatif seperti umur responden, pendapatan responden, jumlah responden serta skor yang diperoleh dari kuesioner yang menggunakan skala likert dan data kualitatif berupa gambaran umum lokasi penelitian, identitas responden dan gambar-gambar berupa foto. Metode pengumpulan data yang digunakan yaitu survey yang dilakukan langsung pada lokasi penelitian, studi kepustakaan dan memberikan kuisioner yang berisi daftar pertanyaan kepada responden untuk diisi sendiri.

\subsection{Variabel penelitian dan Pengukuran}

Variabel dalam penelitian ini yaitu evaluasi kepentingan dan kepercayaan konsumen terhadap atribut buah jeruk. Indiktornya adalah evaluasi kepentingan atribut harga, rasa, warna, aroma, kesegaran, tekstur dan ukuran serta kepercayaan konsumen terhadap atribut harga, rasa, warna, aroma, kesegaran, tekstur, dan ukuran buah jeruk lokal dan impor dengan pengukuran menggunakan skala Likert.

\subsection{Pengujian Instrumen}

Uji validitas instrumen menunjukkan sejauh mana data yang terkumpul tidak menyimpang dari gambaran tentang variabel yang dimaksud (Arikunto, 2006.) hasil pengujian menunjukkan seluruh butir pertanyaan yang berjumlah 21 dalam penelitian ini mempunyai nilai $r$ hitung lebih besar dari $r$ tabel, dengan demikian diketahui bahwa seluruh butir pertanyaan tersebut dikatakan valid sehingga dapat digunanakan dalam penelitian.

Uji reliabilitas menunjukkan bahwa suatu instrumen cukup dapat dipercaya untuk digunakan sebagai alat pengumpul data karena instrumen tersebut sudah cukup baik (Arikunto, 2006). Hasil uji reliabilitas dari seluruh butir pertanyaan memiliki nilai 
koefisien Cronbach's Alpha lebih besar dari 0,6 maka dapat disimpulkan bahwa seluruh butir pertanyaan tersebut reliable.

\subsection{Metode Analisis Data}

Metode analisis data dalam penelitian ini mengunakan analisis Multiatribut Fishbein digunakan untuk mengukur sikap konsumen terhadap berbagai atribut suatu produk. Model multiatribut Fishbein terdiri dari variabel kekuatan dan kepercayaan bahwa buah jeruk lokal dan jeruk impor memiliki semua atribut (bi) dan variabel evaluasi terhadap atribut tersebut (ei) (Setiadi, 2003). Rumus multiatribut Fishbein sebagai berikut.

$$
\text { Ao }=\sum_{I=1}^{n} \text { bi. ei }
$$

Keterangan :

Ao $=$ Sikap terhadap objek

bi = Kekuatan kepercayaan bahwa objek tersebut memiliki atribut $\mathrm{i}$

ei $=$ Evaluasi terhadap atribut $\mathrm{i}$

$\mathrm{N}=$ jumlah atribut yang dimiliki objek

\section{Hasil dan Pembahasan}

\subsection{Karakteristik Responden}

Berdasarkan hasil penelitian, karakteristik jenis kelamin dijelaskan bahwa responden yang membeli buah jeruk lokal maupun jeruk impor di Kota Denpasar adalah perempuan sebanyak $81,67 \%$,kategori umur didominasi oleh kelompok umur 45 s.d 49 tahun sebanyak $21 \%$ kelompok umur 40 s.d 44 tahun sebanyak $20 \%$ Tingkatan pendidikan konsumen buah jeruk lokal dan impor didominasi lulusan diploma/sarjana sebanyak 46,67\%. Karakteristik konsumen berdasarkan pekerjaan sebagai pegawai swasta yaitu sebanyak $40 \%$. Karakteristik pendapatan konsumen tangga mayoritas antara Rp. 2.500 .000 s.d Rp.3.500.000 per bulan sebanyak $25 \%$.

\subsection{Sikap Konsumen terhadap Atribut Buah Jeruk Lokal dan Jeruk Impor}

Sikap konsumen terhadap buah jeruk lokal dan buah jeruk impor di Kota Denpasar dapat dilihat melalui evaluasi kepentingan $\left(\mathrm{e}_{\mathrm{i}}\right)$ dan kepercayaan terhadap atribut $\left(b_{\mathrm{i}}\right)$.

\subsubsection{Evaluasi Konsumen terhadap Kepentingan Atribut (ei)}

Sebelum melakukan pembelian buah jeruk, konsumen akan mengevaluasi atribut apa saja yang dianggap penting untuk diperhatikan sebelum melakukan keputusan pembelian. Hasil rata-rata evaluasi konsumen terhadap atribut buah jeruk dapat dilihat pada Tabel 1 . 
Tabel 1.

Hasil Rata-Rata Evaluasi Kepentingan Atribut (ei) Buah Jeruk

\begin{tabular}{llcc}
\hline No & Atribut & $\begin{array}{c}\text { Evaluasi tingkat } \\
\text { kepentingan }\end{array}$ & $\begin{array}{c}\text { Kategori tingkat } \\
\text { kepentingan }\end{array}$ \\
\hline 1 & Harga buah jeruk & 4,35 & Sangat penting \\
2 & Rasa buah jeruk & 4,67 & Sangat penting \\
3 & Warna buah jeruk & 4,07 & Penting \\
4 & Kesegaran buah jeruk & 4,72 & Sangat penting \\
5 & Ukuran buah jeruk & 3,65 & Penting \\
6 & Tekstur buah jeruk & 3,90 & Penting \\
7 & Aroma buah jeruk & 4,22 & Sangat penting \\
\hline
\end{tabular}

Sumber : diolah dari data primer

Berdasarkan Tabel 1 diketahui bahwa dari ketujuh atribut buah jeruk, terdapat empat atribut yang dinilai sangat penting oleh konsumen yaitu harga, rasa, kesegaran dan aroma buah jeruk. Atribut tersebut merupakan unsur-unsur produk yang dipandang penting oleh konsumen dan dijadikan dasar pengambilan keputusan pembelian (Tjiptono, 2007). Skor tertinggi dari keempat atribut tersebut adalah kesegaran buah jeruk sebesar 4,72 yang menunjukkan bahwa konsumen lebih mengutamakan atribut kesegaran dalam memilih buah jeruk dibandingkan dengan atribut yang lainnya.

\subsubsection{Evaluasi Kekuatan Kepercayaan Konsumen terhadap Atribut Buah Jeruk Lokal dan Impor (bi)}

Penilaian sikap konsumen, selain dari tingkat kepentingan atribut dinilai juga dari tingkat kepercayaan. Hasil dari evaluasi kekuatan kepercayaan konsumen terhadap atribut buah jeruk lokal dan impor dapat dilihat pada Tabel 2.

Tabel 2.

Hasil Rata-Rata Evaluasi Kekuataan Kepercayaan Atribut ( $\left.b_{i}\right)$

\begin{tabular}{llclcl}
\hline \multirow{2}{*}{ No } & \multirow{2}{*}{ Atribut } & \multicolumn{2}{c}{ Buah Jeruk Lokal } & \multicolumn{2}{c}{ Buah Jeruk Impor } \\
\cline { 3 - 6 } & & Skor & Kategori & Skor & Kategori \\
\hline 1 & Harga buah jeruk & 3,3 & Cukup percaya & 2,5 & Tidak percaya \\
2 & Rasa buah jeruk & 3,6 & Percaya & 3,5 & Percaya \\
3 & Warna buah jeruk & 3,3 & Cukup percaya & 4,3 & Sangat percaya \\
4 & Kesegaran buah jeruk & 3,8 & Percaya & 3,2 & Cukup percaya \\
5 & Ukuran buah jeruk & 3,7 & Percaya & 4,0 & Percaya \\
6 & Tekstur buah jeruk & 3,2 & Cukup percaya & 3,7 & Percaya \\
7 & Aroma buah jeruk & 3,6 & Percaya & 3,7 & Percaya \\
\hline
\end{tabular}

Sumber : diolah dari dari data primer 
Tabel 2 menunjukkan bahwa atribut harga buah jeruk lokal lebih dipercaya lebih murah oleh dibandingkan dengan buah jeruk impor. Salah satu konsumen berpendapat buah jeruk lumajang dijual seharga Rp. 12.000 hingga Rp. 15.000 / kg sedangkan Jeruk Mandarin mencapai Rp. 40.000/kg. Harga jeruk impor yang jauh lebih tinggi dari harga jeruk lokal menunjukkan bahwa harga jeruk lokal lebih unggul daripada buah jeruk impor.

Rasa adalah aspek sensorik yang merupakan hal yang sangat berpengaruh dalam beberapa produk. Terdapat empat varian rasa dasar dalam suatu produk yaitu manis, asin, asam, pahit (Wood, 2007). Evaluasi atribut rasa menunjukkan konsumen mempercayai buah jeruk lokal dan buah jeruk impor memiliki rasa yang manis, akan tetapi rata-rata skor menunjukkan bahwa konsumen lebih bersikap positif terhadap atribut rasa buah jeruk lokal. Beberapa konsumen berpendapat jeruk impor memang manis namun terkadang cenderung lebih tawar, sedangkan jeruk lokal memiliki rasa manis yang menyegarkan meskipun ada juga yang asam.

Atribut warna buah jeruk impor dengan jenis jeruk mandarin sangat dipercaya oleh konsumen memiliki warna yang sangat kuning cerah khususnya di Bali, masyarakat menggunakan buah-buahan untuk membuat gebogan dalam upacara keagamaan. Buah jeruk dengan warna kuning kejinggaan lebih dipilih agar memperindah tampilan dari gebogan tersebut.

Atribut kesegaran buah jeruk lokal lebih dipercaya konsumen memiliki kesegaran yang tinggi dibandingkan dengan jeruk impor. Hal ini dipengaruhi oleh jarak distribusi yang lebih dekat dari lokasi panen di Lumajang hingga sampai ke kota Denpasar.

Hasil evaluasi konsumen terhadap atribut ukuran, buah jeruk impor lebih dipercaya memiliki ukuran yang ideal dibandingkan dengan buah jeruk lokal. Beberapa konsumen berpendapat bahwa buah jeruk impor yang terlihat dipasaran memiliki ukuran yang seragam daripada buah jeruk lokal yang ukurannya lebih beragam baik besar ataupun kecil.

Hasil penilaian atribut tekstur menunjukkan buah jeruk impor memiliki nilai yang lebih positif daripada buah jeruk lokal. Konsumen berpendapat beberapa buah jeruk lokal yang dijual dipasaran terdapat burik di kulit buah jeruknya, burik yang terdapat dikulit buah jeruk tersebut disebabkan oleh organisme pengganggu tanaman tertentu, akibatnya kulit buah jeruk berubah

Aroma adalah atribut yang membentuk atribut produk intrinsik. Karena aroma dapat diidentifikasikan ketika produk tersebut akan dikonsumsi (Fandos dan Flavian, 2006). Hasil evaluasi konsumen yaitu buah jeruk impor memiliki aroma yang lebih harum dibandingkan buah jeruk lokal cenderung memiliki aroma asam. 


\subsubsection{Hasil Analisis Sikap Konsumen terhadap Buah Jeruk Lokal dan Buah Jeruk Impor}

Sikap merupakan evaluasi, perasaan emosi, dan kecenderungan tindakan yang dapat menguntungkan atau tidak menguntungkan dan bertahan lama pada seseorang terhadap suatu objek atau gagasan tertentu (Kotler, 2003). Salah satu model sikap konsumen yang paling sering dipakai untuk memahami hubungan antara sikap dan perilaku adalah model sikap multiatribut Fishbein (Schiffman dan Kanuk, 2007). Sikap konsumen tersebut dinilai dari evaluasi konsumen secara keseluruhan terhadap atribut buah jeruk dengan hasil yang dapat dilihat pada Tabel 3.

Tabel 3.

Hasil Analisis Sikap terhadap Buah Jeruk Lokal dan Buah Jeruk Impor

\begin{tabular}{|c|c|c|c|c|c|c|}
\hline \multirow{2}{*}{ No } & \multirow{2}{*}{ Atribut } & \multirow{2}{*}{$\left(e_{i}\right)$} & \multicolumn{2}{|c|}{ Jeruk lokal } & \multicolumn{2}{|c|}{ Jeruk impor } \\
\hline & & & $\left(b_{i}\right)$ & Ao $\left(e_{i} \cdot b_{i}\right)$ & $\left(b_{i}\right)$ & Ao $\left(e_{i} \cdot b_{i}\right)$ \\
\hline 1 & Harga buah jeruk & 4,35 & 3,33 & 14,4855 & 2,45 & 10,6575 \\
\hline 2 & Rasa buah jeruk & 4,67 & 3,55 & 16,5785 & 3,50 & 16,345 \\
\hline 3 & Warna buah jeruk & 4,07 & 3,28 & 13,3496 & 4,30 & 17,501 \\
\hline 4 & Kesegaran buah jeruk & 4,72 & 3,78 & 17,8416 & 3,15 & 14,867 \\
\hline 5 & Ukuran buah jeruk & 3,65 & 3,68 & 13,432 & 4,00 & 14,60 \\
\hline 6 & Tekstur buah jeruk & 3,90 & 3,17 & 12,363 & 3,72 & 14,508 \\
\hline 7 & Aroma buah jeruk & 4,22 & 3,62 & 15,2764 & 3,70 & 15,614 \\
\hline & & & & 103,3266 & & 104,0925 \\
\hline
\end{tabular}

Sumber : diolah dari data primer.

Berdasarkan Tabel 3 diketahui bahwa secara keselurahan nilai sikap konsumen lebih positif terhadap atribut buah jeruk impor dengan total nilai sikap (Ao) sebesar 104,89 sedangkan untuk total nilai sikap (Ao) atribut buah jeruk lokal sebesar 104,12. Sikap konsumen yang cenderung positif menandakan konsumen mendapatkan kepuasan dari buah jeruk impor tersebut dan memperoleh manfaat yang lebih, dapat dikatakan secara keseluruhan buah jeruk impor lebih unggul dibandingkan dengan buah jeruk lokal. Meskipun secara keseluruhan atribut buah jeruk impor memiliki nilai yang lebih positif, beberapa atribut buah jeruk lokal juga memiliki nilai yang tinggi dibandingan dengan atribut buah jeruk impor yaitu, harga, rasa, dan kesegaran

\subsection{Daya Saing Buah Jeruk Lokal dilihat dari Sikap Konsumen terhadap Atribut}

Daya saing berasal dari bahasa latin yaitu competer yang berarti keterlibatan dalam persaingan bisnis dalam sebuah pasar yang menggambarkan kekuatan ekonomi suatu negara (Ambastha, 2004). Berdasarkan hasil analisis Multiatribut Fishbein menunjukkan bahwa sikap konsumen lebih positif terhadap buah jeruk impor yang artinya buah jeruk impor lebih unggul dari buah jeruk lokal. Hal ini menunjukkan 
bahwa ada kecenderungan daya saing buah jeruk lokal masih kurang dibandingkan dengan buah jeruk impor.

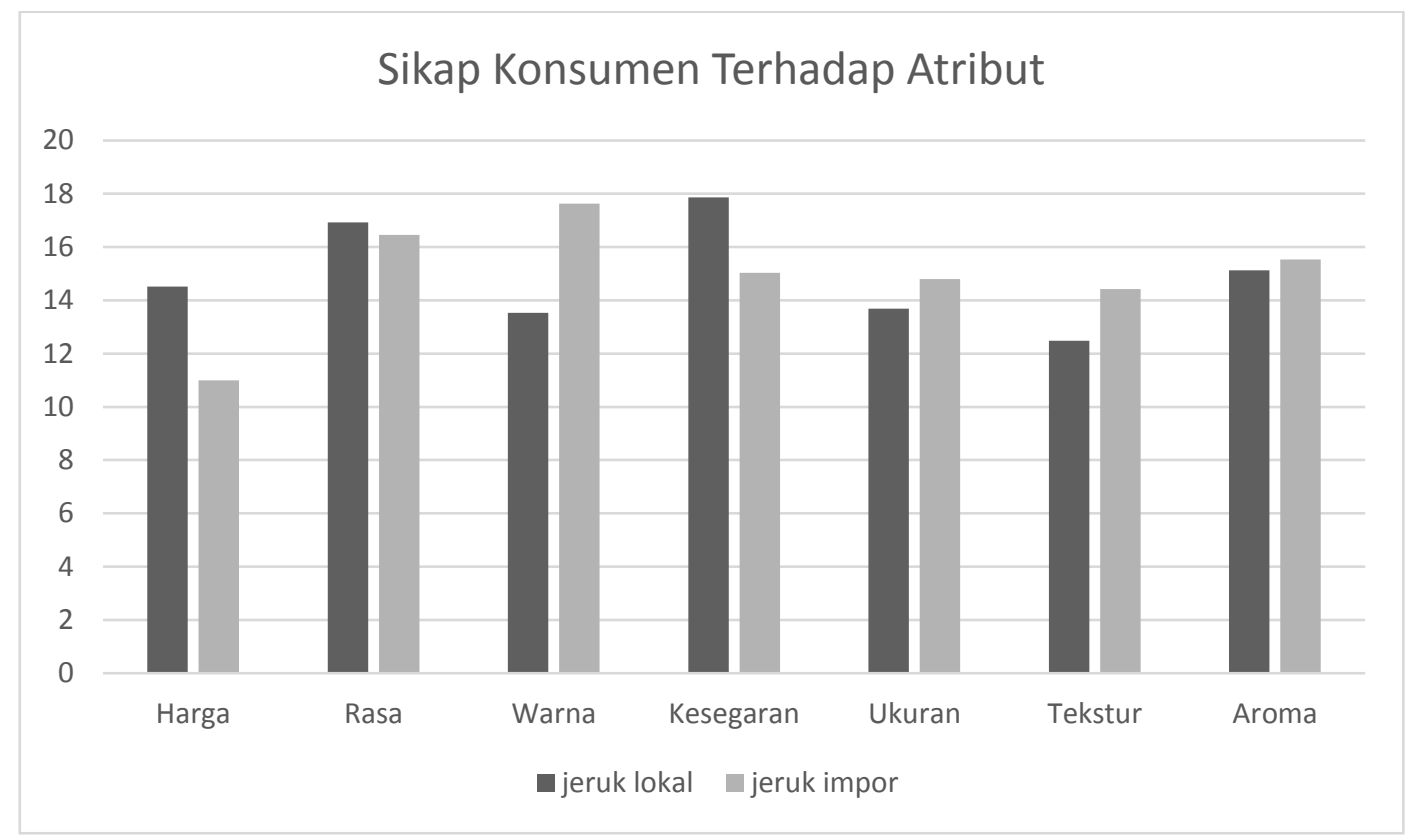

Gambar 1.

Sikap Konsumen terhadap Atribut Buah Jeruk

Gambar 1 menunjukkan atribut-atribut buah jeruk lokal yang perlu diperbaiki agar dapat bersaing dengan buah jeruk impor yaitu, (1) warna kulit buah jeruk; (2) ukuran buah jeruk; (3) tekstur kulit buah jeruk, dan (4) aroma. Peningkatan daya saing buah jeruk lokal juga dilakukan dengan menggalakkan kebijakan perdagangan yang lebih menguntungkan bagi produsen buah lokal seperti membatasi masuknya buah jeruk dari berbagai negara ke Indonesia, sehingga popularitas buah jeruk lokal didalam negeri dapat meningkat. Peningkatan daya saing juga dilakukan dengan mengadakan program dari pemerintah yang terkait dengan pengembangan buah-buahan yang dilakukan mulai dari hulu hingga ke hilir agar kualitas buah jeruk lokal dapat meningkat.

\section{Kesimpulan dan Saran}

\subsection{Kesimpulan}

Berdasarkan hasil analisis dan pembahasan, dapat diperoleh kesimpulan yaitu, dari ketujuh atribut buah jeruk, terdapat empat atribut yang dinilai sangat penting oleh konsumen yaitu harga, rasa, kesegaran dan aroma buah jeruk. Atribut buah jeruk impor yang dipercaya oleh konsumen lebih baik dari buah jeruk lokal yaitu warna, ukuran, aroma dan teksur sedangkan atribut buah jeruk lokal yang dipercaya konsumen lebih baik dari buah jeruk impor yaitu atribut harga,rasa, dan kesegaran. Secara keselurahan nilai sikap konsumen lebih positif terhadap atribut buah jeruk impor dibandingan dengan atribut buah jeruk lokal dengan total nilai sikap (Ao) atribut buah jeruk impor 
sebesar 104,0925 sedangkan untuk total nilai sikap (Ao) atribut buah jeruk lokal sebesar 103,3266. Artinya secara keseluruhan buah jeruk impor lebih unggul dibandingkan dengan buah jeruk lokal. Adanya kencenderungan bahwa daya saing buah jeruk lokal masih lebih rendah dibandingkan dengan buah jeruk impor. Hal itu akan menjadi masalah untuk produk buah jeruk lokal jika tidak diimbangi dengan dukungan dari pemerintah serta peningkatan kualitas buah jeruk lokal dari para petani Indonesia.

\subsection{Saran}

Berdasarkan hasil pembahasan dan kesimpulan, disarankan yang dapat disampaikan yaitu, petani buah jeruk lebih meningkatkan kualitas jeruk lokal, dimana atribut buah jeruk lokal yang masih dianggap kurang baik oleh konsumen dapat segera ditingkatkan. Pemerintah sebaiknya lebih mengalakkan sosialisasi mengenai buah jeruk lokal kepada masyarakat agar dapat meningkatkan kecintaan terhadap produk dalam negeri. Penelitian perlu dilanjutkan dengan sekup wilayah yg lebih luas untuk mengetahui sikap konsumen yang berkaitan dengan atribut buah jeruk, sehingga bisa dilihat faktor-faktor dominan di masing-masing wilayah yg mempengaruhi sikap konsumen untuk suatu produk terutama buah jeruk.

\section{Ucapan Terima Kasih}

Ucapan terima kasih penulis sampaikan kepada kepala dinas PD Pasar Kota Denpasar, manajer supermarket Hardy's, manajer supermarket Tiara Dewata, dan manajer Moena Fresh yang membantu dalam pemberian izin di lokasi penelitian sehingga penelitian ini dapat terlaksana ini hingga dapat dipublikasikan di e-jurnal.

\section{Daftar Pustaka}

Ambastha, A. dan Momaya, K. 2004. Competitiveness of Firms: Review of Theory, frameworks, and Models. [Online]. Tersedia : https://papers.ssrn.com [15 Desember 2016]

Arikunto, S. 2006. Prosedur Penelitian Suatu Pendekatan Praktik. Jakarta :Rineka Cipta.

Fandos, C dan Flavian, C.2006. Intrinsic and Extrinsic Quality Attributes. Loyalty And Buying Intention : Analysis For A PDO Product. [Online]. Tersedia : http://www.emeraldinsight.com [15 Desember 2016]

Tjiptono, F. 2007. Strategi Pemasaran. Edisi kedua. Yogyakarta : Andi.

Kotler, P.2003. Manajemen Pemasaran. Edisi kesebelas, Jakarta: Indeks kelompok Gramedia.

Pusdatin. 2015, Outlook Komoditas Pertanian Subsektor Hortikultura Jeruk. Pusat Data dan Sistem Informasi Pertanian Kementrian Pertanian.Jakarta[online]. Tersedia:http://epublikasi.setjen.pertanian.go.id/pdf [23 November 2016]

Schiffman dan Kanuk. 2007. Perilaku Konsumen. Edisi kedua. Jakarta: PT. Indeks Gramedia.

Setiadi, N. J. 2003. Perilaku Konsumen, Jakarta: Prenada Media 
Suryawardani, I G.A.O. 1999. A Marketing Strategy For Australian Apples and Oranges in Indonesia (case study in Bali and Jakarta). Graduate School of management. Faculty of Economic. The University of Queensland. Australia Wood, Lisa. 2007. Funcional and Symbolic Attributes of Product Selection. [Online] Tersedia : http://www.emeraldinsight.com [17 Desember 2016]

Zulkarnain. 2010. Dasar-dasar Hortikultura. Jakarta: Bumi Aksara. 